\title{
Reactivity of 2-aminothiazole with benzaldehyde and malononitrile
}

Yousseuf Touati ${ }^{1 *}$, Mohammed Benabdallah ${ }^{1}$, M. Pilar Vázquez-Tato ${ }^{2}$, Julio A. Seijas ${ }^{2}$, Noureddine Choukchou-Braham ${ }^{1}$

${ }^{1}$ Laboratoire de Catalyse et Synthèse en Chimie Organique, Faculté des Sciences, Université de Tlemcen, B.P.119, 13000 Tlemcen, Algeria.yousseuf.touati@gmail.com

${ }^{2}$ Facultad de Ciencias. Química Orgánica. Universidad de Santiago de Compostela, Campus de Lugo c/Alfonso Xel Sabios/n.27002-Lugo.Spain.julioa.seijas@usc.es

\begin{abstract}
Nitrogen and sulfur-containing fused heterocyclic molecules can be highly valuable for obtaining biological leads and exploring drug discovery programs. Thiazolo-fused heterocyclic fragments are interesting in pharmaceutical and biomedical research since these scaffolds occur in several natural and biologically active molecules such as anticonvulsant, antidiabetics, antihelminthics and also has depressant effect on the central nervous system. In our studies, we synthesized and optimized some novel class of thiazolo[3,2-a]pyrimidine derivatives by multicomponent reaction of 2aminothiazole with aldehydes aromatic and methylene acids, trying to meet some criteria of green chemistry.
\end{abstract}

\section{Introduction:}

Nitrogen and sulfur-containing fused heterocyclic molecules can be highly valuable for obtaining biological leads and exploring drug discovery programs ${ }^{1}$. Thiazolo-fused heterocyclic fragments are interesting in pharmaceutical and biomedical research since these scaffolds occur in several natural and biologically active molecules such as anticonvulsant ${ }^{2}$, antidiabetics ${ }^{3}$, antihelminthics ${ }^{4}$ and has also depressant effect on the central nervous system ${ }^{5}$. 
In our studies, we synthesized and optimized some novel class of thiazolo[3,2a]pyrimidine derivatives (Figure 1) by multicomponent reaction of 2-aminothiazole with aldehydes aromatic and methylene acids Scheme 1, trying to meet some criteria of green chemistry.<smiles></smiles>

$5 H$-thiazolo[3,2-a]pyrimidine

Figure 1<smiles></smiles>

Scheme 1

\section{Results and discussion:}

The reactivity of the 2-aminothiazole is theoretically similar to the benzoaminothiazoles derivatives present in the literature, ${ }^{6,7}$ and promises to be a good molecular scaffold to construct $5 \mathrm{H}$-thiazolo[3,2-a]pyrimidines skeleton (scheme 2). ${ }^{8}$
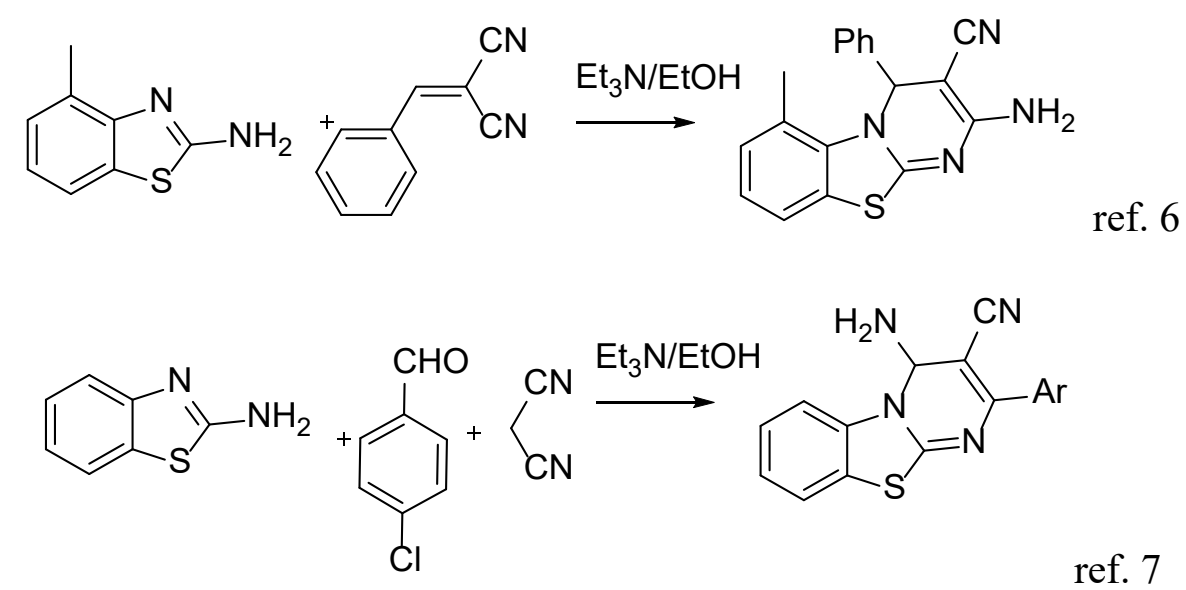

Scheme 2 
However in this communication we report that 2-aminothiazole doesn't give the expected results in the condensation reactions. The one pot reaction in the presence of various bases with both conventional heating and microwaves were negative. The elimination of the base and the heating led to the formation of a product that displays different spectral properties from the expected, since no signal below $\delta=7 \mathrm{ppm}$ was found.

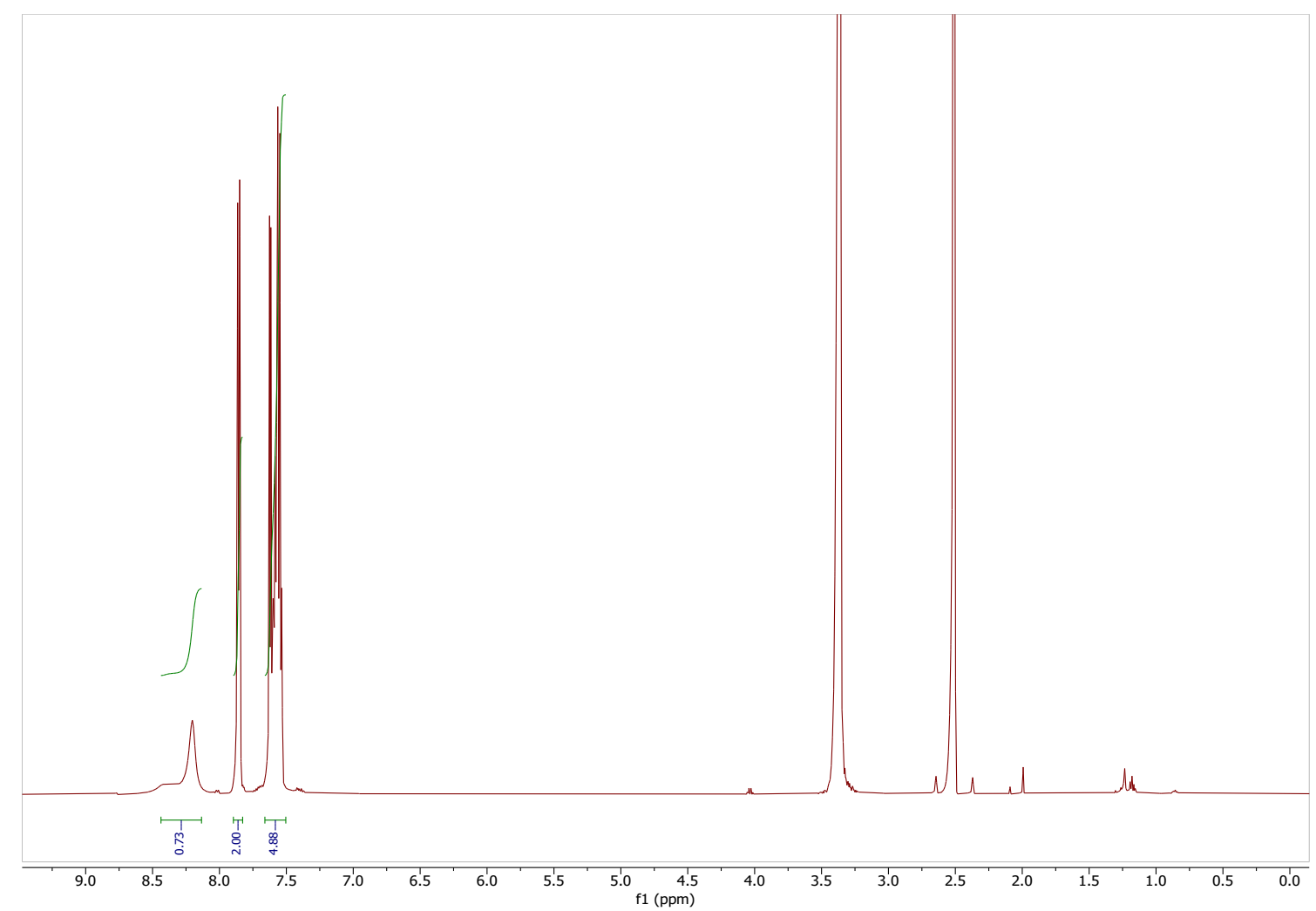

Figure 2. $1 \mathrm{H}$ NMR in DMSO- $\mathrm{d}_{6}$ of the product of condensation

This led us to consider that the structure has no $\mathrm{sp}^{3}$ carbon in the pyrimidine ring together with the presence of an imine instead of an amine in the NMR spectrum $(1 \mathrm{H}$ $\delta=8.20 \mathrm{ppm})$ shown in figure 2.<smiles>N#Cc1c(-c2ccccc2)nc2sccn2c1=N</smiles>

Scheme 3 
With this consideration in our hands, we have to elucidate if the condensation product presented de imino function in the pyridimine ring either in the position 5 ( 2 scheme 3 ) or in position 7 (3 figure 3).

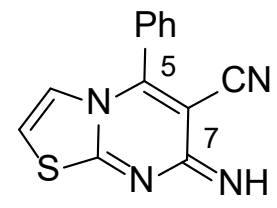

3

\section{Figure 3}

This was clarified by the fragmentation in de mass spectrum of the product, where one of the fragments corresponds to a mass of 187 (N-benzylidynethiazol-2aminium) which only would appear if the structure is the 5-imino compound 2.

\section{Conclusion:}

In this study, we have developed a simple, effective, rapid and green synthesis in the absence of both heating and base in one pot for obtaining new thiazolo-pyrimidines derivatives. Further studies will give a clearer image about the reactivity of the 2aminothiazole, and also optimizations of the reactions process will follow the previous work.

\section{Experimental porcedure}

A mixture of 2-aminothiazole $1.00 \mathrm{gr}(0.01 \mathrm{~mol})$, benzaldehyde $1.06 \operatorname{gr}(0.01$ $\mathrm{mol})$, the malononitrile $0.666 \mathrm{gr}(0.01 \mathrm{~mol})$ dissolved in $25 \mathrm{ml}$ of ethanol was stirred for $24 \mathrm{~h}$ in room temperature $\left(30^{\circ} \mathrm{C}\right)$, after the completion of the reaction (judged from TLC analysis) the mixture was put in the freezer, the solid was filtered. The solid obtained was recrystallized from ethanol/dichloromethane to give a pure compound. ${ }^{1} \mathrm{H}$ NMR (500 MHz, DMSO-d $\left.{ }_{6}\right) \delta 8.20(\mathrm{bs}, 1 \mathrm{H}), 7.86(\mathrm{dd}, \mathrm{J}=8.0,1.6 \mathrm{~Hz}, 2 \mathrm{H}), 7.62(\mathrm{dd}, \mathrm{J}$ $=4.9,0.9 \mathrm{~Hz}, 1 \mathrm{H}), 7.60-7.53(\mathrm{~m}, 4 \mathrm{H}) . \mathrm{MS}(\mathrm{EI}) \mathrm{m} / \mathrm{z}(\%): 252$ (100) $\mathrm{M}^{+}, 251(40), 226$ (21), 187 (28).

\section{Acknowledgements}

The Ministerio de Economía, Industria y Competitividad (Spain) (Project MAT201786109-P) for financial support 


\section{References:}

[1] Kappe, C.O. Curr. Opin. Chem. Biol. 2002, 6, 314-320.

[2] Sharpe, C. J.; Shadbolt, R. S.; Ashferd A.; Ross J. W. J. Med. Chem. 1971, 14, $977-$ 982.

[3] Batool, I., Saeed, A.; Qureshi, I. Z.; Kalsoom, S.; Razzaq, A. Res. Chem. Intermed. 2016, 42, 1139-1163.

[4] Robins, R. K.; Hitchings, G. H.. J. Am. Chem. Soc. 1958, 80, 3449-3457.

[5] Miller, L. F.; Bambory, R. E. J Med Chem, 1972, 15, 415-417.

[6] Hataba, A. A.; Fikry, R. M.; Moustafa; H. Y. J. Indian Chem. Soc. 1997, 74, 818819.

[7] Dandia, A.; Khaturia, S.; Sarawgi, P.; Jain A. Phosphorus, Sulfur, and Silicon, 2007, 182, 2529-2539,

[8] Elassar, A.-Z. A.-A. Sulfur Reports 2002, 23, 47-77. 